\title{
Práticas de "racialização" observadas em narrativas de camponeses que se deslocaram na década de 1950 a cidade de Sobral/Ceará
}

\author{
Practices of "racialization" observed in narratives of peasants \\ who moved in the 1950s to the city of Sobral/Ceará
}

Maria Antonia Veiga Adriao*

Palavras-chave:

Migração

Diversidade

Práticas de Racialização

Keywords:

Migration

Diversity

Practices of Racialization

\begin{abstract}
Resumo: Neste artigo, analiso práticas de "racialização" observadas em narrativas de migrantes que entrevistei para a pesquisa de doutorado, quando investiguei o movimento migratório realizado por camponeses moradores da região "Sertão Centro Norte Cearense" que, em grande medida, teve como destino a cidade de Sobral, também situada nessa região. As fontes que trouxe para este artigo foram narrativas orais; relatórios demográficos do Instituto Brasileiro de Geografia e Estatística (IBGE) e uma bibliografia interdisciplinar que ajudaram a compreender como os entrevistados colocaram em prática seu aprendizado geracional para justificarem suas escolhas na convivência social nessa cidade.
\end{abstract}

\begin{abstract}
In this article, I analyze practices of "racialization" which I observed in migrant narratives that I interviewed for doctoral research, when I investigated the migratory movement carried out by peasants living in the North Center Ceará "Sertão" region, what mostly had the destination the city of Sobral, also located in this region. The sources I brought to this article were oral narratives, demographic reports from the Brazilian Institute of Geography and Statistics (IBGE), and an interdisciplinary bibliography that helped to understand how the interviewees put into practice their generational learning to justify their choices in social coexistence in this city.
\end{abstract}

Recebido em 06 de junho de 2018. Aprovado em 07 de agosto de 2018.

\section{Os Caminhos da Pesquisa}

Analiso, neste artigo, um problema observado nas narrativas de migrantes entrevistados para a pesquisa de doutorado, quando investiguei o movimento migratório realizado por camponeses, moradores da região "Sertão Centro Norte Cearense", ${ }^{1}$ que em sua maioria teve como destino a cidade de Sobral, ${ }^{2}$ também situada nessa região. Ainda que alguns tenham ensaiado morar em outros centros urbanos do Ceará e do Brasil, centrei a pesquisa no movimento intermunicipal com destino a essa cidade, por meio, maiormente, das recordações e percepções das experiências vivenciadas nessa urbe.

Apresentarei inicialmente algumas explicações metodológicas, quando reproduzi muitas das reflexões que realizei na Introdução e em tópicos do Segundo Capítulo do citado trabalho.

Considero necessário destacar que muitos estudos migratórios analisam as dificuldades que migrantes enfrentam no campo da moradia, do trabalho, da qualificação profissional, das dificuldades de adaptação às novas circunstâncias, importantes porque refletem problemas estruturais os quais uma vez superados, contribuem para a

\footnotetext{
* Doutora em História Social Universidade Federal do Ceará (UFC). Mestre em História do Brasil Universidade Federal de Pernambuco (UFPE). Licenciatura em História Universidade Estadual Vale do Acaraú (UVA). Professora adjunta Curso de História da Universidade Estadual Vale do Acaraú (UVA).E-mail: mavaadri@hotmail.com
} 
fixação da residência, embora esta fixação exorasse mais, porque passa pelo campo da estabilidade emocional e psíquica do migrante ao se ver "desterritorializado" ou desinstalado de seu tempo social (HAESBAERT, 2005).

No que se refere ao grupo entrevistado ${ }^{3}$ não foi diferente, já que igualmente colocaram em destaque esses problemas; contudo, alguns enfatizaram nas relações com os vizinhos, algo que chamou atenção, porque ficou no campo das "relações de racialização", tomando emprestado essa noção desenvolvida por Rios e Mattos (2005), a qual retornarei mais adiante.

Trouxe neste artigo, portanto, uma reflexão sobre as práticas de "racialização" observadas nas recordações das vivências na cidade de Sobral.

Ainda que nas décadas de 1950 a 1980 (período da pesquisa), houvesse um movimento de camponeses cearenses para outros Estados brasileiros, sobretudo para o Sudeste do país, ligado aos ciclos econômicos e às secas bem maior do que o existente na atual conjuntura, movimento que pude observar com alguns dos inquiridos que se deslocaram para outros estados (mas não permaneceram) ou que possuem parentes migrados fora do Ceará, considerava importante conhecer outras interpretações, em uma perspectiva talvez de "ego-história" (CHAUNU et. al, 1989), por também ser filha de camponeses que migraram a Sobral nos anos de 1970.

Porquanto, entre aqueles que se deslocaram no decorrer da seca de $1958^{4}$ a Sobral, por exemplo, quatro dos 27 (vinte e sete) entrevistados, um homem e três mulheres, apenas este ressaltou esse fenômeno climático como provocador. As senhoras justificaram obrigações familiares, o que vai de encontro a situações recorrentes que não reverberam nesses estudos como os valores culturais da época.

É preciso lembrar que o IBGE, ao incluir na pesquisa demográfica de 1960 a mobilidade intermunicipal, pois até então abrangia apenas a inter-regional, apresentou dados que revelaram que o movimento migratório interno compreende um dinamismo não circunscrito à busca por empregos nas fábricas das grandes cidades, uma ideia defendida a partir dos anos de 1940, conforme Santos (2009).
Conclui-se, pelas estatísticas, que todos os municípios e todas as regiões do país atraíam, assim como perdiam populações rural e urbana (tomando estes conceitos do IBGE que orientava suas estatísticas entre populações: urbana, suburbana e rural).

É fundamental perceber que essa mobilidade de populações rural e urbana surge equilibrada, não se percebendo os centros urbanos ganhando mais populações como passou a acontecer a partir dos anos de 1970 (por razões que não serão analisadas neste texto), com alguma exceção (SANTOS, 2009). Nesse sentido, no Censo IBGE 1970, já se percebe alteração significativa do movimento populacional, com um deslocamento maior de populações às zonas urbanas, não necessariamente saídas das zonas rurais. Contudo, não estudei os camponeses que emigraram dessa cidade no período, nem outro segmento social que entrou ou saiu, apenas o grupo referendado.

Não obstante, Sobral surge como o maior núcleo urbano do interior do Estado ainda no século XIX (BARBOSA et al., 2000), com uma economia comercial que aglutinava a produção regional em seu mercado, e em consequência, ingressou na fase industrial ainda na segunda metade desse século, mantendo-se com uma produção extrativista de sementes (AGUIAR JUNIOR, 2005), até a renovação de sua indústria com os subsídios e incentivos da Superintendência Para o Desenvolvimento do Nordeste (SUDENE) na década de 1960 e 1970, quando esta cidade assumiu a posição de "Cidade Polo", ou "Polo de Desenvolvimento regional", uma das políticas de incremento à economia, alvitrada pela ditadura civil militar. ${ }^{5}$

Ressalto ainda que, na década de 1950 (período em que os entrevistados começaram a chegar, pois o primeiro chegou em 1951), o IBGE constatou que: "Dos 79 Municípios cearenses, oito tinham população superior a cinqüenta [sic] mil habitantes: Fortaleza (270.169), Sobral (70.011) [...]". Portanto, esse município já possuiu a segunda maior população do Ceará e, por sua vez, uma das maiores populações do país consoante se observa no Anuário Estatístico do Brasil de 1950, surgindo entre àqueles com mais de 50 mil habitantes, total de 77 (setenta e sete municípios), enquanto os 1.817 
(mil, oitocentos e dezessete) restantes, possuíam menos de 50 mil habitantes.

Apesar disso, não estou querendo afirmar que, por Sobral posicionar-se na região do Sertão Centro Norte do Ceará como o maior município e, por conseguinte, a maior cidade, e mesmo em nível nacional estando entre os maiores municípios, isso ocasionasse a migração para seu centro urbano, o qual não concentrava como já assinalei, a exemplo das outras cidades brasileiras, ${ }^{6}$ a maior população, pois esta se situava maiormente, na zona rural.

Todavia, pelo que observei, o centro urbano dessa cidade atraía por dois motivos: por possuir características comerciais e industriais, e, por outro lado, nas suas fronteiras ou na sua área periférica, como já sinalizava o IBGE, porque orientava seus relatórios dividindo os distritos municipais entre urbano, suburbano e rural; assim, ao atravessar o centro urbano dessa cidade podia-se até plantar um roçado, como alguns migrantes o fizeram.

Considero interessante destacar, ainda, a maneira como os entrevistados representaram o lugar onde moravam: "Sertão" e "sertãozim" aparecem nas falas juntamente com "Lugarzim", "Interiorzim" e "Povoadozim", os quais substituem o nome da comunidade onde nasceram.

Logo não analisarei o aspecto conceitual do entendimento "fisiográfico" respectivo à divisão realizada pelo IBGE, ou as circunstâncias da divisão política que se estabeleceu com a criação da república brasileira, menos as diferenças históricas elaboradas no decorrer da colonização que elaboraram o par sertão e litoral, nem como permanecem sendo ressignificadas. Ou historiar como as categorias "sertão", "campo", "rural" e como seus opostos surgem nos discursos e nas práticas sociais, acadêmicas e políticas, nem como se confundem ou se alternam nesses discursos ou nessas práticas.

Contudo, autores como Arruda (2000), Ivone Barbosa (1998), Queiroz (1978), Williams (1990) refletiram a respeito, concordando cada um no seu campo que, a divisão social, cultural e política observada entre sertão e cidade, rural e urbano, campo e cidade ignora, citando Queiroz (1978, p. 267), que: “[...] quando concebidos como dualidades, tradicional-moderno, rural-urbano, e outros pares de conceitos que se acredita opostos, a dedução lógica é de que são mutuamente exclusivos; dedução lógica dizemos, e portanto, que não apela para a experiência humana [...]".

Apelando para a "experiência humana" é que respeitei os termos utilizados pelos entrevistados, não por parecer natural que se colocassem dessa maneira, mas pelo fato de "sertão" representar um lugar de suas referências sociais, que nesse sentido não é "atemporal", embora nas narrativas emerja como se fosse, segundo Ivone Barbosa (1998, p. 28), “[...] a categoria sertão não guarda nenhuma essencialidade fora das experiências sociais dos sujeitos que o nomeiam".

Desse modo, concordo também com Edward Thompson (1998, p. 20), quando percebeu que a identidade social era apropriada pelos trabalhadores investigados por ele conforme seus interesses: "[Era] possível perceber no mesmo indivíduo identidades que se alternam, uma deferente, a outra rebelde." (ADRIAO, 2017, p. 16).

Portanto, como não foi meu objeto de estudo, não pude me aprofundar, mas cogitei que remeter-se a "sertão" era uma forma de opor temporalidades. Isso porque os migrantes na cidade experimentaram uma descontinuidade temporal, neste caso, de incertezas, que abrangia um novo endereço com vizinhos desconhecidos, uma nova moradia, novos amigos, novo trabalho, novas espacialidades que representavam perdas materiais e simbólicas difíceis de serem superadas a não ser, ressaltando suas experiências em um lugar que precisava ser melhor, neste caso, diverso da cidade, questão refletida por pesquisadores como Haesbaert (2005) quando observou que os migrantes se sentiam "destituídos" do que fazia sentido em suas vidas e procuravam compensar reelaborando o passado, fazendo-o parecer melhor.

Como a fonte oral foi central neste trabalho, inclusive, por esta oportunizar àqueles que emigraram a essa cidade relatarem suas "percepções" ou suas formas de "expressão do mundo social", no motivo do deslocamento para Sobral, e na razão de permanecer, o que estavam elegendo como importante "no campo de forças e 
como campo das lutas" políticas, citando Bourdieu (2000, p. 164-165).

Portanto, acreditando nessa possibilidade, não tratei os entrevistados como simples informantes ou como testemunhas de ocorrências do passado, evitando trazer suas narrativas como anexos. Procurei percebê-los como segmentos de uma cidade que se refazia com suas chegadas e com suas atuações sociais, porque mesmo ignotas, mesmo silenciosas e até "licenciosas" abriram percursos e refizeram mapas (CERTEAU, 1994).

Desse modo, propus-me a um diálogo sobre suas recordações a respeito do movimento que realizaram e em como estabeleceram residência em Sobral. Para tanto, realizei visitas sistemáticas às suas residências ou aos locais indicados. Esse método sugerido por Portelli (2001) constituiuse, inicialmente, de trocas de informações com abertura para indagações do tipo: "por que você precisa gravar nossa voz aí?", "por que você precisa filmar?", "o que você vai ganhar com isso?", portanto, para exporem suas dúvidas a respeito da pesquisa.

Quando optei, entre conversas informais e formais, sendo estas últimas as que foram gravadas em áudio e vídeo, pela elaboração de uma interlocução que representasse interesses mútuos e, assim, até certo ponto, fluida de espontaneidade, sem um questionário dirigido a não ser com as perguntas básicas de identificação, ${ }^{7}$ embora tendo claro que, meu propósito era um, e o deles era outro.

Possibilidade analisada por autores como Avelino (2001, p. 225), pois: “[...] permite-nos entender a dimensão do outro que constrói o seu próprio domínio do passado, com serenidade, na organização da sua memória a partir daquela situação.".

No entanto, elaborar uma análise que consiga expressar esse diálogo e a relação de confiança que se construiu não tem sido fácil, porque se estabeleceu um compromisso ético indefinido, de não exceder suas reflexões, ou mais bem explicando, não extrapolar seus relatos representativos de suas experiências e impressões do vivido (KHOURY, 2001).

Não obstante, não extrapolar seus relatos não significa deixar de fazer críticas ou não colocar suas narrativas em perspectiva temporal e analisálas refletidamente no contexto no qual se inserem. Significa afirmar, por exemplo, que não posso determinar se os entrevistados silenciaram ou omitiram circunstâncias deliberadamente como se tivessem planejado. Mas, por outro lado, posso cogitar que algo foi silenciado, sobretudo quando a voz embarga e o silêncio passa a falar pelos entrevistados. E ainda posso cogitar que tal situação foi esquecida. No entanto, em ambas as situações, quando acontecem, o inquirido apresenta sinais.

Assim, revelo um dos motivos de ter feito também a opção de analisar as narrativas e até as outras fontes de forma "indiciária", pensando desse modo, nas proposições de Ginzburg (1989). Quero demonstrar com isso que os excertos das entrevistas e os relatórios do IBGE apenas apresentam sinais de como foi viver nessa "urbe" sob resquícios do período pós-abolição, sobretudo porque, pelo espaço reservado para este artigo, não há como aprofundar o assunto.

O outro motivo de optar pelo método proposto por esse autor foi que não objetivei investigar as práticas de racialização entre os migrantes; portanto, não houve como já sublinhado, um questionário dirigido aos migrantes para que respondessem ou narrassem situações de discriminação social e racial ou de preconceitos de quaisquer tipos. A ideia era ouvi-los a respeito da decisão de emigrar, das circunstâncias que consideravam provocadoras do deslocamento e sobre as vivências em Sobral.

Nesse sentido, a questão surgiu quando alguns migrantes relatavam situações vividas nessa cidade relacionadas com lazer, namoro, casamento, relações com vizinhos. Ao sistematizar os relatos, percebi que precisava refletir a respeito em razão de essa questão se fazer presente nessas sessões das narrativas.

E, embora o diálogo com esses interlocutores tenha sido permeado pelos cuidados recomendados à pesquisa com a fonte oral, mormente, dos cuidados necessários quando se constroem relações de reciprocidade, isso não quer dizer que não haja a possibilidade de discordâncias após a escrita divulgada, o que obviamente será respeitado, 
porque desencontros temporais entre o pesquisador e entrevistados podem acontecer quando se trata da fonte oral.

Portelli (2000, p. 298) advertiu que: "As histórias de vida e os relatos pessoais dependem do tempo, pelo simples fato de sofrerem acréscimos e subtrações em cada dia da vida do narrador". Nessa perspectiva, é possível que um entrevistado, ao ter acesso a este artigo ou a minha Tese, faça uma crítica à minha interpretação ou uma autocrítica à experiência relatada, e, desse modo, possa dissentir e até solicitar a alteração do seu relato.

Quem trabalha com entrevistas ou com relatos orais tem muito claro que se trata de uma abordagem aberta à intervenção do narrador em qualquer época. "Portanto, uma história de vida é algo vivo. Sempre é um trabalho em evolução, pois os narradores examinam a imagem do seu próprio passado enquanto caminham", esclarece Portelli (2000, p. 298).

Igualmente Schmidt (2012, p. 87) defendeu que as recordações não representam "essências" intactas a serem "resgatadas", uma vez que são resultados de vivências passadas, mas também da interpretação dessas vivências; nesse sentido, perceber como os sujeitos reelaboram suas recordações deve compor o método de análise (SCHMIDT, 2012, p. 87).

Ainda é preciso explicar que, embora a escrita seja um processo solitário, não havendo como mensurar o que representava para os inquiridos, assumi o compromisso de entregar uma cópia das entrevistas gravadas em Digital Versatile DiscRecordable (DVR-R). Todos assistiram sozinhos ou com familiares e comentaram positivamente, nomeadamente por se verem na "televisão", e pela comoção que causou recordar de situações vividas coletiva ou individualmente, sendo algumas desconhecidas para os mais jovens.

Outro ponto de relevo é que não houve censura no que assistiram, ou seja, na gravação audiovisual. Os pontos das entrevistas criticados aconteceram do modo como acredito, acontecem em toda pesquisa, quando um inquirido solicita para "tal parte" não ser gravada.

No que concerne às outras fontes, procurei analisá-las principalmente com a perspectiva metodológica sugerida por Revel (1998), pois não se tratava de um movimento circunscrito às vivências dos migrantes e às suas interpretações. Perscrutei, assim, outras fontes que apresentassem vestígios da migração investigada, ou que refletissem a situação da população habitante da região, ou da cidade de Sobral, ou os problemas acentuados pelos entrevistados. Assim, cheguei a artigos e enunciados de um periódico local (fundado em 1918), a relatórios dos Censos Demográficos do IBGE, a mapas cartográficos, à legislação trabalhista e sobre a terra, a cópias de fotografias do centro urbano de Sobral e dos migrantes, a arquivos de uma escola, de sindicatos, do setor pessoal de uma fábrica, entre outros.

A própria cidade foi pensada como um "documento-monumento" (LE GOFF, 1996) ou como um "imenso arquivo" (GINZBURG, 1991) de memórias sobrepostas materiais e imateriais, ao observar as ruas citadas, os bairros, as fábricas em funcionamento ou falidas, as escolas pleiteadas, os santuários, as residências onde boa parte reside desde que chegou, o mercado, quando quase dá para vê-los labutando, pelejando, exorcismando o tempo. E, enquanto trabalhavam em prol de suas permanências, essa cidade modificava sua paisagem, seus percursos, suas fronteiras, seus parâmetros de convivência, reformava, portanto, seu centro urbano, uma questão que abordei no quarto capítulo.

\section{“Assim A Sociedade Era Muito Boa!”}

Retomando o problema inicial, no respectivo às práticas de racialização observadas nas recordações dos migrantes, destaquei a paráfrase: "Assim a sociedade era muito boa" como enunciado para esse Tópico do artigo, porque refere-se à narrativa de uma das migrantes citadas, indica maneiras de viver as normas sociais e familiares na cidade de Sobral.

Trouxe, inicialmente, Dona Maria da Conceição Aguiar ${ }^{8}$, considerando que ela se remete ao seu aprendizado geracional sem expandilo a práticas fora do âmbito familiar, restritas principalmente, às recordações das vivências com 
sua genitora, não associando esse aprendizado a outras circunstâncias de suas vivências, de modo que apresentasse indícios de como essas práticas reverberavam no âmbito social maior. Já as outras migrantes citadas na sequência abrem a esta perspectiva.

- Ah! Aqui era coisa pouca, só assim, de gente passando. Sei lá, as coisas, os homem eram diferentes, eram diferentes! Os rapazes, os homens eram diferentes nesse tempo! [...] A mamãe? Só se for mais outra pessoa, só não, andar aqui em Sobral só? Pelo menos no nosso sertão, ela não deixava a gente sair, mas [...] só que a mamãe, a mamãe me amarrava, porque não deixava eu sair não. A mamãe dizia num dá certo não, na casa de comade Júlia tem um rapazim lá, que tem uma bodeguinha, mas ele é moreno, mas ele é moreno Não dá certo não, não vai cair na conversa dele não! Ai eu fiquei tristonha aqui em Sobral [...], com saudade, porque lá se juntava as moças, os rapazes, a gente brincava do anel [...]. Eu sempre com saudade, saudade do meu sertãozim [...] aquelas missas que a gente ia em São Vicente [...] eu tinha voltado com muito gosto [...], mas, depois com a continuação do tempo. né? Aí começaram: - Maria vamo pra missa? Ai a gente ia na Santa Casa [capela do hospital]; ia no Sumaré [bairro vizinho], - bora Maria pra missa? [...] com a continuação do tempo né, nós se acostumamos aqui, porque foi o jeito mesmo, era coisa de precisão mesmo, porque nós num tinha mais nada [...], com a continuação do tempo nós tava assim, gostando, gostando. Fui acostumada no sertão, fui acostumada no sertão e fiquei nessa arrumação. A Graça aí, ia muito pras festa nos Vinte [clube social], mas eu não ia não [...], e outra coisa, eu não queria deixar minha mãe só não [...]. Sei lá, fulano de tal moreno e, além disso, minha filha, também bebe [...], tudo isso ela botava na minha cabeça, [...] porque era moreno mesmo, se bem que moreno não era problema pra mim não, mas [...]. (AGUIAR, 2014).

Mariazinha, como preferia ser nominada, recebeu-me na cozinha de sua residência de forma extrovertida e satisfeita pela oportunidade de colocar suas impressões a respeito de seu deslocamento para Sobral. Aposentada, dona de casa, então com 74 anos, residia na mesma rua do bairro da Santa Casa desde que chegara nessa urbe. Colocou-se como solteira em razão de ter preferido cuidar de sua genitora, mas especialmente por ouvir suas recomendações, suas notações a respeito dos rapazes, em particular, seus vizinhos "morenos" como acentua no relato.

Morava com sua irmã (casada) na residência da família, espólio dos tempos difíceis, da migração e da ideia que se refez através dos anos, também lugar-comum entre os entrevistados, de que as famílias deviam morar conjuntas para superar mais facilmente as dificuldades financeiras e o estranhamento cultural.

Sua entrevista foi realizada em várias sessões principalmente pela forma como exteriorizou suas recordações, repletas de pleonasmo textual e gestual, quando procurou deixar claro, teatralizando até, os motivos de sua nostalgia ao lembrar-se das brincadeiras dos tempos de moça, as canções que ouvia e as danças que executava com os rapazes (valsa; xote), narrando as tardes agradáveis que passava com parentes e vizinhos, no "alpendre" da residência da família, onde morava.

Essa senhora apresentou-se como filha de "pequenos proprietários", termo o qual esse segmento dos entrevistados se autoconferia. Essa foi uma categoria difícil de ser definida entre os migrantes, porque eram jovens quando se deslocaram e dessa maneira, não recordavam ou não sabiam mensurar ${ }^{9}$ o que possuíam como herdeiros.

Enquanto alguns migrantes preferiram inicialmente ressaltar suas impressões a respeito de outros deslocamentos que realizaram, ou a respeito das dificuldades com a moradia, ou com o desemprego até encontrar alguma estabilidade trabalhista, ou sobre a falta que fez a escola, ${ }^{10}$ essa migrante apresentou sua versão dos acontecimentos vivenciados em 1958 provocadores do deslocamento, para, em seguida, enfatizar como vivenciou os primeiros anos em Sobral, a solidão que sentia, a nostalgia e os conselhos de sua genitora que tentava, pelo que fica dito, conformá-la diante das novas circunstâncias. 
O relato dessa senhora revelou um lado das vivências dos migrantes importante de pôr em evidência por esclarecer que as dificuldades experienciadas pelos camponeses caracterizavamse por idade, por gênero e pela posição assumida no âmbito familiar ou social. Sua genitora (viúva) e seus irmãos mais velhos se concentraram em aumentar a renda familiar e em como "criar" um negócio para a família, e depois de "criado", como mantê-lo rentável, (uma "bodeguinha" adquirida com a venda de uma das propriedades da família, elaborada na sala principal da casa onde residiam), a qual se manteve até seu irmão, que a gerenciava, desistir e emigrar para Fortaleza, capital do Estado.

Portanto, essa senhora dividiu essas urgências do cotidiano com a ideia de refazer seu círculo de convivência. Mas, como isso não foi possível, passou a viver "tristonha". É importante notar que uma das aprendizagens mais difíceis que Mariazinha teve de enfrentar foi o distanciamento das relações sociais cultivadas anteriormente, sem poder retomá-las em Sobral, sem poder desenvolver novas relações afetivas com pessoas que ela aprendeu a perceber como não seguras a essa possibilidade, como seus vizinhos já aludidos.

A narrativa oral é importante nesses casos porque introduz perspectiva. Enquanto procurava conhecer os problemas que teriam gerado a migração dos camponeses, assim como as dificuldades enfrentadas com a moradia em Sobral, pensando neste caso a cidade como uma "continuidade" temporal e espacial ${ }^{11}$, quando os problemas estariam ligados somente à sobrevivência material, não obstante, essa senhora trouxe outras circunstâncias que excederam minha proposição.

Maria da Conceição praticamente iniciou sua narrativa acentuando sua aversão à migração para Sobral e à vida celibatária, revelando sua decepção com toda a situação, esforçando-se para acentuar as minúcias de sua experiência, e assim, recordando os motivos que a fizeram desistir dos pretendentes a matrimônio que apareceram, ao relatar os pareceres de sua genitora para que evitasse se envolver com os "rapazes morenos" que lhe demonstrassem interesse. Ela pode ter recusado a se casar por outro motivo; entretanto, pela ênfase que deu à questão, trouxe o indício de que poderia ter-se casado com o jovem pleiteante, se não fossem os conselhos de sua mãe.

Ressalto que essa senhora não reivindicou o lugar de descendente de colonizadores e de proprietários de escravos, como fizera a outra senhora citada na sequência, nem se distinguiu de seus vizinhos contemporâneos, ou de seus vizinhos pretéritos, apesar de, ao rememorar às tardes que passava com amigos, tenha deixado sinais de que dispunha de tempo livre e de pessoas que compartilhavam da mesma posição. Posição que talvez a distanciasse dos "rapazes morenos" da comunidade onde morava e motivo de - é possível presumir - ter provocado as preocupações de sua genitora.

Não obstante, quem sabe o grau de não urbanização de bairros como o Santa Casa onde Mariazinha residia, tenha contribuído para exacerbar seu estado de desconfiança e de insatisfação, porque a população ali residente, além de desconhecida, era rarefeita como ela observa: "Ah! Aqui era coisa pouca. Só assim, de gente passando". Então, essa declaração leva a imaginar um bairro sem ruas definidas, sem capina, com frentes de residências e quintais desencontrados e espaçados, onde à noite não era possível transitar considerando a escuridão, pois não havia iluminação pública, entre outras dificuldades relatadas não por dona Maria da Conceição, mas pela irmã dessa migrante, Dona Maria das Graças da Silva ${ }^{12}$, também entrevistada.

E não estou querendo afirmar com isso que o "sertão" fosse dessemelhante se comparado a essa estética urbana; todavia, era diferente no sentido de permitir caminhar com confiança sem temer surpresas. E os costumes do local, em relação ao uso comum dos espaços, possuíam regras elaboradas na convivência que legitimava possivelmente até as diferenças entre os segmentos sociais.

Todavia, se a mãe dessa senhora fazia recomendações discricionárias a propósito de com quem ela deveria se relacionar, classificando os jovens pela tonalidade da pele, pode-se pensar que ela vivia em uma conjuntura que reverberava essa situação. Assim, o problema entrava em relação com o tempo presente de forma naturalizada, como 
herança cultural que podia apenas ser repassada à nova geração da melhor forma.

Entretanto, essa é uma reflexão que pode ser avaliada apenas pelo modo como se inscreve na narrativa e nas práticas cotidianas relatadas, já que não investiguei mais profundamente, como já assinalado, e a questão foi abordada sem que houvesse o objetivo de investigá-la.

E não se pode esquecer, concordando com Candau (2011, p. 141), que se trata de uma "reapropriação" ou reelaboração do que foi vivenciado com sua genitora. Porque segundo esse autor: "Ao mesmo tempo em que constrói sua identidade pessoal por uma totalização provisória de seu passado, o indivíduo realiza, portanto, a aprendizagem da alteridade".

Não obstante, Dona Maria da Conceição não foi a única inquirida a acentuar relações discriminatórias apreendidas em sua educação geracional. Dona Zenite Carneiro Soares ${ }^{13}$ igualmente relatou práticas nesse sentido em sua experiência como moradora da cidade de Sobral:

- Pois é, nessa época o bairro do Tamarindo era um bairro grande, num tava tão dividido como é hoje não! Tinha os bazares. Eu mais minhas duas irmãs, nós frequentávamos o bazar da casa da dona Quinquinha, [...] quem dançava na casa da Dona Quinquinha não dançava lá na casa Dda dona Maria, que'ra uma mulher que morava ali perto da beira do rio. Ninguém era intrigado. As moças eram divididas, os rapazes muito pretos assim, não dançavam na casa da Dona Quinquinha [...]. A gente não podia trocar de rapaz. Quando você fosse ao bazar, você levava seu par. Nem bêbado, ninguém fumava cigarro dentro da sala, naquele tempo tinha respeito. Hoje num tem não! Ia bem vestido, num tinha negócio. E quem era que falava em bermuda naquela época? [...] Eu me sentia feliz com aquilo, minha mãe ficava na calçada [...] meu pai também, várias vezes, dançou nos bazares. E assim a sociedade era muito boa! [...]. (SOARES, 2014).

Dona Zenite Soares é pedagoga com especialização na área de Educação pela Universidade Estadual Vale do Acaraú (UVA), aposentada como professora do município de Sobral, tinha 77 anos de idade quando a entrevistei. Emigrou para essa cidade também na década de 1950, mas não em decorrência da seca de 1958. Chegara antes, "foi entre os anos de 53 para 54 que minha mãe veio pra cá" (SOARES, 2014).

Essa senhora, diferentemente de Dona Maria da Conceição, reconhece-se como descendente de proprietários de terras e de escravos, por conseguinte, como integrante do segmento de brancos moradores dessa cidade, e aprendeu a considerar importante preservar seu aprendizado geracional e seu "lugar social".

Sua entrevista foi dividida em oito sessões, quando em cada uma procurou explorar melhor um tema de seu interesse. Dessa forma, foi mais do tipo autobiográfico, tendo também como característica um tom professoral e explicativo de quem tinha muito a ensinar, muito ao estilo defendido por Benjamim (1994), quando chamava atenção para situações às quais sua geração vivenciou que faziam falta aos jovens.

No que se refere ao trecho da sua narrativa, a exemplo de Maria da Conceição, não pesquisava essa questão quando a entrevistei porque não é preciso enfatizar que, precisaria de uma abordagem mais elaborada, inclusive, fundamentada não apenas em como acontecera a abolição nessa cidade e na região, e em como ficou a população remanescente da escravidão; porém, precisaria apresentar uma conjectura que justificasse estudar como se estabeleceram as práticas de racialização pós-abolição, nessa cidade.

Trata-se, portanto, de um problema que carece de exclusividade pela complexidade que apresenta. Não que não me interessasse de forma até autobiográfica; no entanto, não foi meu objetivo. E, embora fosse previsível que esse assunto reverberasse nas narrativas - considerando que as questões trazidas por Dona Zenite não eram desconhecidas quando propus pesquisar a mobilidade da população que morava adjacente a Sobral -, permaneci com o plano de construir diálogos com os entrevistados de modo a deixá-los livres nas suas narrativas o mais possível, e analisar as circunstâncias recorrentes, mas relacionadas à migração para Sobral. 
No que respeita ao relato de Dona Zenite, esta senhora falou de sua experiência nos clubes sociais da cidade, todavia, já casada, dos "bailes" que frequentava e da etiqueta que precisava ser seguida pelas senhoras, mesmo acompanhadas de seus esposos. E, desse modo, recordou as práticas de discriminação social existentes que separavam ricos e pobres, brancos e pretos (vou empregar esta categoria reportando-me ao trecho citado dessa senhora), homens e mulheres, e outras frações sociais, a exemplo do que acontecia nos "bazares" realizados no bairro onde residia, antes de se casar.

Não obstante, a grande maioria dos entrevistados nasceu na primeira metade do século XX - entre 1930 e 1940 -; nesse sentido, é provável que resquícios da cultura escravocrata ainda estivessem impregnados nos seios das famílias fossem estas proprietárias, fossem expropriadas, fossem ricas, fossem pobres, fossem brancas, fossem pretas, fossem sobralenses ou migrantes dessa região do Sertão Norte do Ceará, ou de outras regiões.

A despeito disso, concordo com Rios e Mattos (2005, p. 31), quando defenderam a necessidade de estudar as "relações de racialização" existentes no Brasil e não apenas o "preconceito racial". Porquanto, essa questão, ou seja, o processo de "racialização e discriminação racial" vivenciado pelas populações derivadas da escravidão passou por descontinuidade temporal com a abolição, no sentido de essa prática ter-se renovado nas décadas que se seguiram.

Logo, essas autoras defendem que o racismo que se observa ainda no presentemente vivido, não deve ser naturalizado como consequência da escravidão e da organização social predominante na época. São abordagens distintas quando se analisam os anos logo após a abolição do regime escravocrata, em comparação com as décadas posteriores, porque as relações entre os segmentos sociais passaram por alteração não apenas em decorrência da abolição e do advento do capitalismo industrial que criou novos estratos sociais, mas porque reverberam, por exemplo, a política de Estado de embranquecimento da população brasileira com a imigração estrangeira, entre outras circunstâncias.
Não obstante, Dona Zenite aprendeu a defender a discriminação social entre "pretos" e "brancos" e entre trabalhadores e proprietários como necessária para manter a "boa sociedade". Além da frequência aos clubes sociais da cidade, explicou sua participação em espaços menos formais constituídos por jovens de suas relações, denominados de "bazares". Em algumas passagens de sua entrevista, procurou deixar evidentes as suas opções, o seu "aprendizado de berço" e os valores que aprendeu a defender, ao assinalar os "bons modos" dos rapazes e das moças com os quais se relacionava, o que abrangia conhecer o "lugar social" que ocupavam.

Essa senhora igualmente sublinhou as inquietações no atinente ao consumo de bebida (alcoólica), e acrescentou o cuidado com o consumo de "cigarro", observando, ainda, a etiqueta do vestuário adequado e todo o procedimento esperado nos "bazares" - onde os jovens de seu bairro se dividiam: alguns compareciam à residência de "Dona Quinquinha" e outros, à residência de "Dona Maria".

Uma categorização que, como se nota, abrangia objetivamente também os jovens pela tonalidade da pele, porque aqueles "muito pretos" podiam comparecer somente à casa de Dona Maria, deixando dito que, o outro grupo, de "brancos", comparecia à outra residência. Embora essa orientação compreendesse, igualmente, a preocupação com a conduta social aguardada - ensinada por indicações dos genitores e nos exemplos de como proceder na vida social - não importava apenas o tom da pele.

Isso em razão de essa senhora comparecer aos bazares acompanhada de seus pais, os quais se posicionavam na "calçada", onde ocorriam essas reuniões, ou dentro, participando também. As consignações sociais notadas na narrativa de Dona Zenite Soares, diferentemente das sugeridas na narrativa de Dona Maria da Conceição, ganharam sentido e se ressignificaram nessas vivências. Estendiam-se provavelmente a outras situações do cotidiano não relatadas por essa senhora.

Poutignat e Streiff-Fenart (2011, p. 141) defenderam que: "[...] a etnicidade é uma forma de 
organização social, baseada na atribuição categorial que classifica as pessoas em função de sua origem suposta, que se acha validada na interação social pela ativação de signos culturais socialmente diferenciadores." Nessa perspectiva, percebe-se uma legitimação dessas práticas culturais, embora não seja possível mensurar até que ponto os grupos citados por essa migrante se dividiam, aceitavam ou até "astuciavam" alterações nas normas de convivência social.

É oportuno lembrar que Dona Maria das Graças da Silva, mencionada anteriormente, também migrou nos anos de 1950. Apesar de ser irmã de Dona Maria da Conceição, não relatou sua experiência nesse campo com sua genitora. No entanto, recordou também que a assiduidade aos clubes sociais de Sobral estava submetida grosso modo, "ao que as pessoas faziam" "porque podiam pegar fama". Nesse sentido, assinalou que existia um clube alcunhado de "Panela", porque era frequentado pelas "empregadas domésticas", e que "quem não queria pegar fama não frequentava o Panela”. Ocasião em que preferiu explicar por metáfora, porque passou a relatar como educara seus sobrinhos-filhos, porque ajudara a criar três órfãos antes de casar-se e conceber seu próprio filho.

Veja que "doméstica" estava associado a algo indesejável, que ninguém deveria querer ser ou parecer ser; logo, é presumível que a segregação notada tivesse relação com o lugar social ocupado pelos "pretos" em Sobral naqueles anos, exemplificado pelos bazares recordados por Dona Zenite Soares. E ambos representam indícios de mais práticas de racialização nessa cidade, e que essas práticas podiam ser percebidas nos espaços sociais, mas, igualmente, nos espaços físicos da cidade.

Essa questão pode ser observada em outras pesquisas como a de Weimer (2015). Esse autor analisou narrativas de migrantes que realizaram o movimento "rural-urbano" no Estado do Rio Grande do Sul, entre 1920 e 1950, os quais, ao contrário dos que eu trouxe neste artigo, inscreveram-se como descendentes de escravos que vivenciaram "Interlúdios de racialização", como assinala o autor, no espaço urbano onde tentaram estabelecer residência. $\mathrm{O}$ que não significa, como nos casos que ora analiso, que não houvesse práticas semelhantes onde moravam, Percebo apenas que, ao relatarem suas vivências no centro urbano, denunciaram estágios de "racialização", como esse autor igualmente defende, sublinhando entre outros exemplos, a "cor da pele" "como critério seletivo da entrada em bailes" (WEIMER, 2015, p, 158).

Como objetivei apenas refletir sobre as práticas de racialização que podem ser observadas em algumas narrativas, e, por conseguinte, nas maneiras de viver de alguns migrantes, não será possível aprofundar essa questão de modo a deixar mais esclarecido como se elaboraram essas fronteiras nos espaços da cidade de Sobral, e mais, como foram perdendo força no decorrer do século XX. Contudo, analisei mais refletidamente na tese já referendada.

Ainda é preciso ressaltar que, as relações de racialização nunca foram totalmente "inflexíveis" nem no período da escravidão, como é possível observar em estudos como o de Guedes (2008). Para esse autor, a "cor da pele" era uma "categoria móvel" para escravos e trabalhadores livres; por essa razão, precisa ser percebida como "histórica" em uma perspectiva de abrigar a diversidade social que a classificava e a deslocava, de forma a corresponder aos interesses variados das camadas sociais, e por outra, das políticas estatais.

É importante entender que esses valores observados nas narrativas citadas responderam a interesses diversos e intercambiáveis, ou seja, a interesses em movimento de adaptação às novas situações, sem querer dizer, dessa forma, que a realidade anterior não fosse permeada por racismos. Contudo, na convivência em Sobral, os migrantes precisaram rever noções, acrescentar parâmetros, abrir-se às junções e disjunções de outra sociedade, de outras práticas sociais.

É preciso deixar claro, nesse sentido, que famílias como a de Mariazinha e a de Dona Zenite não se colocavam cingidas em si mesmas. Acautelavam-se nas interações com os sobralenses classificados como "morenos" e "pretos", sem que se possa refletir apenas com suas narrativas, o que significaram essas noções, como fizeram Guedes (2008) e Weimar (2015), que estudaram como se 
formaram as diversas categorias de negros no Brasil escravocrata e pós-abolição.

Não obstante, não significa dizer que essas famílias se recusaram a integrar-se às novas situações que modificaram às circunstâncias relatadas, porque um destaque da narrativa de Dona Zenite não citada neste trabalho é que ela relata o casamento de uma filha com "um negro", fato que sofreu desaprovação familiar, mas a união aconteceu, sinalizando, portanto, uma alteração nas maneiras de viver dos entrevistados.

\section{Notas}

1 A região do percurso dos migrantes até a década de 1960 compreendia três "microrregiões fisiográficas" distintas: Litoral, com 18 municípios; Sertão Centro Norte, com 24 e Ibiapaba com 12 municípios (IBGE, 1960, p. 80; 90). No entanto, como a maior parte dos municípios de onde se originaram os migrantes assim como Sobral estão situados na região Sertão Centro Norte, tomei essa região como referência.

2 A cidade de Sobral passou à década de 1970 como cidade polo e cidade líder da microrregião homônima (Sobral). A respeito: "Além da definição das Grandes Regiões do país, esta divisão regional proposta no final da década de 1960 buscou 'demarcar espaços homogêneos e espaços polarizados' no território brasileiro [...]. Em relação à definição dos espaços homogêneos, pode-se dizer que estes foram tidos como uma 'forma de organização em torno da produção' e seriam expressos 'por combinações de fatores físicos, sociais e econômicos"' (CONTEL, 2014, p. 8, grifo meu).

3 Entrevistei 27 migrantes ex-moradores de comunidades, povoações, vilas urbanas, fazendas, sítios situados em municípios como Meruoca, Alcântaras, Massapê, Cariré, Santana do Acaraú, Acaraú, Martinópole, Coreaú, Santa Quitéria, Canindé, Tianguá, Itapipoca, entre outros.

4 Sobre a seca de 1958, é importante ver a seguinte pesquisa: Duarte, 2002.

5 Muito esclarecedoras as reflexões de Contel (2014) referendadas na nota 2 .

6 Para Santos (2009, p. 29) "O Brasil foi, durante muitos séculos, grande arquipélago, formado por subespaços que evoluíram segundo lógicas próprias, ditadas em grande parte por suas relações com o mundo exterior. Havia, sem dúvida, para cada um desses subespaços, pólos [sic] dinâmicos internos.”.

7 Sobre as diversas formas entrevistas, consultar Thompson (1998).

8 Entrevista de Maria da Conceição Aguiar concedida a Maria Antônia Veiga Adrião. Sobral, set. 2014. Gravação realizada em audiovisual, editada em DVD-R.
9 A respeito das noções de grande, média e pequena propriedade, ver: Andrade, 1980.

10 Para uma atualização dessa questão, ver: Adriao, 2016.

11 Sobre as temporalidades distintas observadas na cidade, consultar: Lefebvre, 1991.

12 Entrevista de Maria das Graças Aguiar da Silva concedida a Maria Antônia Veiga Adrião. Sobral, ago. 2014. Gravação realizada em audiovisual, editada em DVD-R.

13 Entrevista de Zenite Carneiro Soares concedida a Maria Antônia Veiga Adrião. Sobral, out. 2014. Gravação realizada em audiovisual, editada em DVD-R.

\section{Referências}

ADRIÃO, Maria Antonia Veiga. Introdução. In: Os Caminhos do Sol: Atravessar Veredas na Cidade Escurece a Vista (Migração Sertão-Cidade de Sobral 1950-1980). 2017. Tese (Doutorado em História Social) - Programa de Pós-Graduação em História, Universidade Federal do Ceará, Fortaleza, 2017, p. 15-35.

"Pra botar os filhos no colégio": educação escolar na perspectiva de um migrante. Cadernos do CEOM: Acervos Para História da Educação, Chapecó, v. 29, n. 44, p. 89-97, jun. 2016, disponível em: <http://bell.unochapeco.edu.br/revistas/index. php/rcc $>$. Acesso em: 5 ago. 2016.

AGUIAR, Maria Da Conceição Entrevista concedida a Maria Antônia Veiga Adrião. Transcrição manuscrita, Sobral, set. 2014.

AGUIAR JUNIOR, Paulo Rocha. O Rio Acaraú e a Cidade de Sobral - Ce. In: A cidade e o

Rio: Produção do Espaço Urbano em Sobral-Ceará. 2005. Dissertação (Mestrado em Desenvolvimento e Meio Ambiente) - Programa de Pós-Graduação em Arquitetura, Universidade Federal do Ceará, Fortaleza, 2005, p. 25-59.

ANDRADE, Manuel Correia De. Latifúndio, Expropriação e Miséria. In: Latifúndio

e Reforma Agrária no Brasil. São Paulo: Duas Cidades, 1980, p. 24-25. 
ARRUDA, Gilmar. Cidades e Sertões: Entre a História e a Memória. Bauru: EDUSC, 2000.

AVELINO, Yvone. Dias. Experiências e Trajetórias de Vida. As Tramas da Memória Universitária a Partir de Depoimentos Orais. Projeto História, São Paulo, n. 22, p. 223-238, jun. 2001.

BARBOSA, Marta Emisia Jacinto; et al. Introdução. In: Sobral: Patrimônio Nacional. Sobral: Prefeitura Municipal de Sobral, 2000, p. 7-10.

BARBOSA, Ivone Cordeiro. Sertão: O Espaço do Outro. In: Sertão: Um Lugar-Incomum... 1988. Tese (Doutorado em História) - Programa de Pós-Graduação Doutorado em História, Universidade de São Paulo, São Paulo, 1998, p. 27-55.

BENJAMIN, Walter. O Narrador: Considerações Sobre a Obra de Nikolai Leskov. In: . Magia e

Técnica, Arte e Política: Ensaios Sobre Literatura e História da Cultura. Trad. de Sérgio Paulo Rouanet. 7. ed. São Paulo: Brasiliense, 1994, p. 197-221.

BOURDIEU, Pierre. A Representação Política: Elementos Para Uma Teoria Do Campo Político. In: O Poder Simbólico. Trad. de F. Tomaz. 3. ed. Rio de Janeiro: Bertrand Brasil, 2000, p. 163-207.

CANDAU, Joël. O Jogo Social da Memória e da Identidade (2): Fundar, Construir. In:

Memória e Identidade. Tradução de Maria Leticia Ferreira. São Paulo, 2011, p. 137-179.

CERTEAU, Michel de. Práticas de Espaço. In: A Invenção do Cotidiano: 1. Artes de Fazer. Trad. de E. F. Alves. Petrópolis: Vozes, 1994, p. 169-217.

CHAUNU, Pierre; et al. Ensaios de Ego-História. Lisboa: Edições 70, 1989.

CONTEL, Fábio Betioli. As Divisões Regionais do IBGE no Século XX (1942, 1970 e 1990). Terra Brasilis: (Nova Série). Revista da Rede Brasileira de História da Geografia e Geografia Histórica, Rio de Janeiro, v. 3, p. 1-20, 2014. Disponível em: <https:// terrabrasilis.revues.org/990-3-document-sans-titre. pdf>. Acesso em: 10 fev. 2016.

DUARTE, Renato Santos (Org.). A Seca de 1958: Uma Avaliação Pelo ETENE. In: A Seca de 1958: Uma Avaliação Pelo ETENE. Fortaleza: Banco do Nordeste; Recife: Fundação Joaquim Nabuco, 2002, p. 11-21.

INSTITUTO BRASILEIRO DE GEOGRAFIA E ESTATÍSTICA (IBGE). Relação dos Municípios de População Superior a 50.000 Habitantes. Anuário Estatístico Brasileiro, Ano XI, 1950. Rio de Janeiro, 1950, p. 44. Disponível em: <https://biblioteca.ibge. gov.br/visualizacao/periodicos/20/aeb_1950.pdf $>$. Acesso em: 24 jul. 2018.

VI Recenseamento Geral do Brasil: Censo Demográfico 1950 Ceará. Rio de Janeiro: IBGE, 1951. p. 12-19. Disponível em: <http://biblioteca. ibge.gov.br/ visualizacao/periodicos/70/cd_1950_ ce.pdf $>$. Acesso em: 7 jul. 2013.

População: Resultados Segundo as Zonas Fisiográficas e os Municípios. Censo Demográfico de 1960 Ceará: VII Recenseamento Geral do Brasil. Rio de Janeiro: IBGE, 1960. p. 79-93. Disponível em: <http://biblioteca.ibge.gov.br/visualizacao/ periodicos/68/cd_1960_v1_t4_ce.pdf $>$. Acesso em: 8 jul. 2013.

- Relação Dos Municípios do Estado do Ceará... Censo Demográfico Ceará: VIII Recenseamento Geral 1970. Rio de Janeiro: IBGE, 1973. p. LXXIII-LXXVI. Disponível em: <http:// biblioteca.ibge.gov.br/visualizacao/periodicos/720/ cd_1970_v1_t7_ce.pdf>. Acesso em: 5 ago. 2016.

GINZBURG, Carlo. Sinais: Raízes de Um Paradigma Indiciário. In: - Mitos, Emblemas, Sinais: Morfologia e História. Trad. de F. Carotti. São Paulo: Companhia das Letras, 1989, p. 143-179.

O Nome e o Como: Troca Desigual e Mercado Historiográfico. In: A Micro-

História e Outros Ensaios. Trad. Ayala Monteiro. Rio de Janeiro: Bertrand Brasil, 1991, p. 169-178. 
GUEDES, Roberto. A Todos é Permitido Empregarse Naquele Ministério Que a Condição de Cada Um Tem Adotado. In: Egressos do Cativeiro: Trabalho, Família, Aliança e Mobilidade Social (Porto Feliz, São Paulo, c, 1798-c.1850). Rio de Janeiro: Mauad X: FAPERJ, 2008, p. 69-125.

HAESBAERT, Rogério. Migração e Desterritorialização. In: FERREIRA NETO, HELION Póvoa e; PACELLI, Ademir. (Org.). Cruzando Fronteiras Disciplinares: Um Panorama dos Estudos Migratórios. Rio de Janeiro: Revan, 2005, p. 35-46.

KHOURY, Yara Aun. Narrativas Orais na Investigação da História Social. Projeto História, São Paulo, n. 22, p. 79-103, jun. 2001.

LEFEBVRE, Henri. Continuidades e Descontinuidades. In:___ O Direito à Cidade. Trad. R. E. Frias. São Paulo: Moraes, 1991, p. 51-57.

LE GOFF, Jacques. Documento/Monumento. In: História e Memória. Trad. Suzana Ferreira Borges. 4. ed. Campinas: Editora da Unicamp, 1996, p. 535-549.

MENEZES, Marilda Aparecida de. Itinerários Migratórios e Trajetórias Sociais. In: Rede e Enredos nas Trilhas dos Migrantes: Um Estudo de Famílias de Camponeses-Migrantes. Rio de Janeiro: Relume Dumará; João Pessoa: Editora da Universidade Federal da Paraíba, 2002, p. 45-86.

PORTELLI, Alessandro. História Oral Como Gênero. Trad. Maria Therezinha Janine Ribeiro. Projeto História, São Paulo, n. 22, p. 9-36, jun. 2001.

"O Momento da Minha Vida": Funções do Tempo na História Oral. Trad. H. Hughes; Y. A. Khoury. Estórias no Tempo. In: FENELON, Déa Ribeiro (Org.). Muitas Memórias, Outras Histórias. São Paulo: Olho d’Água, 2000, p. 296-313.

POUTIGNAT, Philippe; STREIFF-FENART, Jocelyne. O Domínio da Etnicidade: As Questões-
Chave. In: Teorias da Etnicidade: Seguido de Grupos Étnicos e Suas Fronteiras de Fredrik Barth. Trad. E. Fernandes. 2. ed. São Paulo: Ed. UNESP, 2011, p. 141-172.

QUEIROZ, Maria Isaura Pereira De. Dialética do Rural e do Urbano: Exemplos Brasileiros. In: Cultura, Sociedade Rural, Sociedade Urbana no Brasil: ensaios. Rio de Janeiro: Editora da Universidade de São Paulo, 1978, p. 263-311.

REVEL, Jacques (Org.). Microanálise e Construção do Social. In: __ Jogos de Escalas: a Experiência da Microanálise. Trad. Dora Rocha. Rio de Janeiro: FGV, 1998, p. 15-38.

RIOS, Ana Maria; MATTOS, Hebe. Experiência e Narrativa - O "Pós-Abolição" Como Problema Histórico. In: RIOS, Ana Lugão; MATTOS, Hebe. Memórias do Cativeiro: Família, Trabalho, e Cidadania no Pós-Abolição. Rio de Janeiro: Civilização Brasileira, 2005, p. 13-34.

SANTOS, Milton. A Urbanização Pretérita. In: A Urbanização Brasileira. 5. ed. São Paulo: Editora da Universidade de São Paulo, 2009, p. 19-30.

SCHMIDT, Benito Bisso. Do Que Falamos Quando Empregamos o Termo "Subjetividade" na Prática da História Oral? In: LAVERDI, R. et al. História Oral, Desigualdades e Diferenças. Recife: Editora Universitária da UFPE; Florianópolis: Editora da UFSC, 2012, p. 83-96.

SILVA, Maria das Graças Aguiar da. Entrevista Concedida a Maria Antonia Veiga Adrião. Transcrição Manuscrita, Sobral, ago. 2014.

SOARES, Zenite Carneiro. Entrevista Concedida a Maria Antônia Veiga Adrião. Transcrição manuscrita, Sobral, out. 2014.

THOMPSON, Paul. A Entrevista. In: A voz do Passado: História oral. Trad. Lólio Lourenço de Oliveira. 2. ed. Rio de Janeiro: Paz e Terra, 1998, p. 254-278. 
THOMPSON, Edward Palmer. Introdução: Costume e Cultura. In: Costumes em

Comum: Estudos Sobre a Cultura Popular. Trad. Rosaura Eichemberg. São Paulo: Companhia das Letras, 1998, p. 13-24.

WILLIAMS, Raymond. O Campo e a Cidade: Na História e na Literatura. 1. impr. Trad. Paulo
Henriques Britto. São Paulo: Companhia das Letras, 1990, p. 11-20.

WEIMER, Rodrigo de Azevedo. Geração de Migrantes. In: Felisberta e Sua Gente:

Consciência Histórica e Racialização Em uma Família Negra no Pós-Emancipação Rio-Grandense. Rio de Janeiro: Editora FGV, 2015, p. 137-182. 